\section{Impact of bacterial priming on some stress tolerance mecha- nisms and growth of cold stressed wheat seedlings}

\author{
Mohammed E.H. Osman, \\ Wedad A. Kasim, ' Mohammed N. Omar, ${ }^{2}$ \\ Islam A. Abd El-Daim, ${ }^{2,3}$ Sarosh Bejai, ${ }^{3}$ \\ Johan Meijer ${ }^{3}$ \\ 'Botany Department, Faculty of Science, \\ Tanta University, Egypt; 'Department of \\ Microbiology, Soils Water and \\ Environment Research Institute, \\ Agriculture Research Centre, Giza, Egypt; \\ ${ }^{3}$ Department of Plant Biology and Forest \\ Genetics, Uppsala BioCenter, Swedish \\ University of Agricultural Sciences and \\ Linnean Center for Plant Biology, \\ Uppsala, Sweden
}

\begin{abstract}
The potential to enhance growth of cold stressed wheat by seed treatment (priming) with the beneficial bacteria Bacillus amyloliquefaciens 5113 and Azospirillum brasilense N040 were tested. Results showed an improved ability of bacteria-treated seedlings to survive at $-5^{\circ} \mathrm{C}$ up to $12 \mathrm{~h}$. Cold stress increased transcript levels of three stress marker genes and increased activity for the ascorbate-glutathione redox enzymes. However, primed and stressed seedlings generally showed smaller effects on the stress markers correlating with better growth and improved stress tolerance. Bacterial priming to improve crop plant performance at low temperature seems a useful strategy to explore further.
\end{abstract}

\section{Introduction}

Environmental stress causes great losses in crop production where abiotic factors like soil salinity, drought and extreme temperature constitute the most fatal problems. Low temperature is the major limiting factor for crop production in regions where cold periods or freezing occurs annually. Late frost also causes major damage to seedlings in many areas. Exposure of plants to low temperatures leads to the generation of reactive oxygen species (ROS). ROS cause oxidative damage of many different compounds impairing cell function. ${ }^{1}$ Since oxidants have different properties the antioxidant defense constitutes both enzymatic and non-enzymatic components distributed over different compartments throughout plant cells to maximize protection. An important role in plant defense has been attributed to the ascorbate-glutathione pathway due to its ability to maintain high levels of antioxidants by regenerating used antioxidants.

The synthesis of numerous biological compounds and the regulation of many metabolic processes depend on $\mathrm{Cl}$ metabolism. ${ }^{2}$ The availability of $\mathrm{C} 1$ units affects the capacity to produce osmolytes and thus how plants resist abiotic stress by reducing water content, phase changes and ice formation. Methionine is a precursor for the major methyl group S-adenosyl-Met (SAM) formed by SAM synthetase (SAMS), which can be used as an indicator of the $\mathrm{C} 1$ status.

It is a challenge for plants to support protein folding at different temperatures to maintain protein function. Heat shock proteins (HSP) belong to the chaperone superfamily of proteins which enhance folding and stability of many proteins. HSP can also provide cryo-protective effects and maintain membrane integrity during stress conditions. ${ }^{3}$ Many HSP are known to be induced by abiotic stress. ${ }^{3}$

Abiotic stress tolerance of plants is a complex process involving modifications at many levels. ${ }^{4}$ Plants can be primed to enhance tolerance to stress by certain chemicals or biological agents, e.g. plant growth promoting bacteria (PGPB). ${ }^{5}$ Priming has low fitness costs for the plant and of high interest to explore for durable plant protection being a cost effective biotechnological alternative to breeding. In this study we aimed to induce freezing stress tolerance in wheat using two PGPB strains. The rationale behind this is that different kinds of abiotic stress share common features such as changes in water status and osmotic balance. We have earlier found that these bacterial strains prime drought tolerance in wheat and our hypothesis was that we therefore also could prime improved cold tolerance. ${ }^{6}$

\section{Materials and Methods}

\section{Plant growth and treatments}

Wheat (Triticum aestivum L.) cv. Sids1 is a widely cultivated Egyptian spring cultivar that is relatively sensitive to abiotic stress. ${ }^{7}$ Grains were surface disinfected using calcium hypochlorite. ${ }^{8}$ Two bacterial strains were used for priming of wheat grains. Azospirillum brasilense N040 is tolerant to osmotic stress and decreases salt stress in barley. ${ }^{9}$ Bacillus amyloliquefaciens 5113 prime disease resistance $^{10}$ and abiotic stress tolerance in oilseed rape (Meijer, unpublished). Bacteria were grown in $\mathrm{LB}$ medium for $48 \mathrm{~h}$ at $28^{\circ} \mathrm{C}$ and the density determined by colony forming unit (CFU) analysis. Grains were soaked in solu-
Correspondence: Islam A. Abd El-Daim, Department of Forest Mycology and Pathology, Uppsala BioCenter, Swedish University of Agricultural Sciences (SLU), Box 7026, SE75007 Uppsala, Sweden.

Tel. +46.186 .72708 - Fax: +46.186 .73599$

E-mail: islam.abdeldaim@slu.se

Key words: bacteria, cold stress, priming, stress tolerance, wheat.

Contributions: the authors contributed equally.

Conflict of interests: the authors declare no potential conflict of interests.

Funding: These studies were supported by The Swedish Research Council for Environment, Agricultural Sciences and Spatial Planning (FORMAS) and the Swedish Institute (SI). Funding for plant growth facilities were provided by KFI-VR.

Received for publication: 26 February 2013

Revision received: 4 July 2013

Accepted for publication: 5 July 2013

This work is licensed under a Creative Commons Attribution NonCommercial 3.0 License (CC BYNC 3.0).

(c)Copyright M.E.H. Osman et al., 2013

Licensee PAGEPress srl, Italy

International Journal of Plant Biology 2013; 4:e8 doi:10.4081/pb.2013.e8

tions containing $10^{7}$ bacteria $\mathrm{mL}^{-1}$ for $2 \mathrm{~h}$ at $28^{\circ} \mathrm{C}$ with shaking while control seeds were soaked in water. Three primed or un-primed grains were sown in $6 \mathrm{~cm}^{2}$ pots containing sterile soil (50\% low humidity peat and 50\% average humidity peat) (Weibulls, Hammenhög, Sweden) in controlled environment with $22 / 16^{\circ} \mathrm{C}$ (day/night), $16 / 8 \mathrm{~h}$ photoperiod, $450 \mu \mathrm{mol} \mathrm{m} \mathrm{m}^{-2} \mathrm{~s}^{-1}$ and $80 \%$ humidity. Plants were watered daily during $12 \mathrm{~d}$ and then shifted to growth cabinets (Percival Scientific, IA) with settings as above but exposed to $-5^{\circ} \mathrm{C}$ in order to stress the plants while another set of plants was kept under normal conditions as control. Sampling of plants was carried out at 0, 6, 12 and $24 \mathrm{~h}$. Samples for laboratory analysis were frozen in liquid nitrogen and kept at $-72^{\circ} \mathrm{C}$.

\section{Plant growth analysis}

At each time point, 40 plants were randomly selected, randomly divided into two groups and kept at normal conditions stated above to allow recovery. After three days plant survival of each group was measured relative the initial number where control plants showed 100\% survival. Immediately after sampling, seedlings were washed and dried between two filter papers. Fresh weight was recorded before the 
samples were dried at $50^{\circ} \mathrm{C}$ until constant weight. The difference between fresh and dry weight was used to calculate the water content of shoots. Data based on replicates (at least six times) were subjected to analysis of variance (ANOVA) to determine the significance between the treatments using Costat (CoHort software, CA, USA).

\section{Enzyme and transcript assays}

Ascorbate peroxidase (APX), mono-dehydroascorbate reductase (MDHAR), dehydroascorbate reductase (DHAR) and glutathione reductase (GR) were assayed by homogenizing $200 \mathrm{mg}$ frozen plant material in $1 \mathrm{~mL}$ extraction buffer and after centrifugation the supernatant was analyzed for enzymes activity. ${ }^{11}$

Expression of ascorbate peroxidase (APXI), S-adenosylmethionine synthetase (SAMS1) and heat shock protein (HSP17.8) genes was analyzed using semi-quantitative RT-PCR. Total RNA was extracted from leaves using a Plant RNA Mini Kit (Omega Bio-Tek, USA) followed by DNase I treatment. First strand cDNA was synthesized from $500 \mathrm{ng}$ of RNA using SuperScript III (Invitrogen, USA). Primer3 software was used to design gene specific primers (Table 1). ${ }^{12}$ The invariant ACTIN cytoskeleton gene was used to normalize the expression levels. As a negative control, reaction mixture without cDNA was used. The RTPCR reaction used Dream Taq polymerase enzyme (Fermentas, Finland) and the following parameters: denaturation for $2 \mathrm{~min}$ at $94^{\circ} \mathrm{C} ; 30$ cycles of $1 \mathrm{~min}$ at $95^{\circ} \mathrm{C}, 50 \mathrm{sec}$ at $54^{\circ} \mathrm{C}$ and $1 \mathrm{~min}$ at $72^{\circ} \mathrm{C}$; and finally $10 \mathrm{~min}$ at $72^{\circ} \mathrm{C}$. Prior experiments showed that 30 cycles provided transcript levels being in a linear range. Samples were separated on a $1 \%$ agarose gel and bands quantified using the Quantity One software (Bio-Rad) with lane-based background subtraction and normalization of the bands to compensate for differences in loading. The band intensity was quantified using volume units (pixels $/ \mathrm{mm}^{2}$ ) and shown as the relative fold expression at zero time.

\section{Results}

\section{Plant growth and survival}

The effect of freezing on wheat growth was severe. Exposing wheat seedlings to $-5^{\circ} \mathrm{C}$

Table 1. Gene specific primers and genes from Triticum aestivum used for RT-PCR analyses

\begin{tabular}{|c|c|c|}
\hline Gene & NCBI number & Primer sequence \\
\hline$A P X 1$ & AF387739.1 & $\begin{array}{l}\text { forward, 5'- GGAGGCTTCCTGATGCTG-3' } \\
\text { reverse, 5'-CGGCGTAGTCCTTGAAGAAT-3' }\end{array}$ \\
\hline TmSAMS1 & EU399630.1 & $\begin{array}{l}\text { forward, 5'-GACCCAGGTGACTGTGGAGT-3' } \\
\text { reverse, 5'-AGGCACGCCAATAGCATAAG-3' }\end{array}$ \\
\hline HSP17.8 & AF350423.1 & $\begin{array}{l}\text { forward, 5'-AGGATGTTCGGACTGGAGAC-3' } \\
\text { reverse, 5'-ACGAACTTGCGCATCATCT-3' }\end{array}$ \\
\hline TmACTIN & AB181991.1 & $\begin{array}{l}\text { forward, } 5 \text {-CAGTTGCCCAGCAATGTATG-3 } \\
\text { reverse, } 5 \text {-AGCAATTCCAGGAAACATGG-3 }\end{array}$ \\
\hline
\end{tabular}

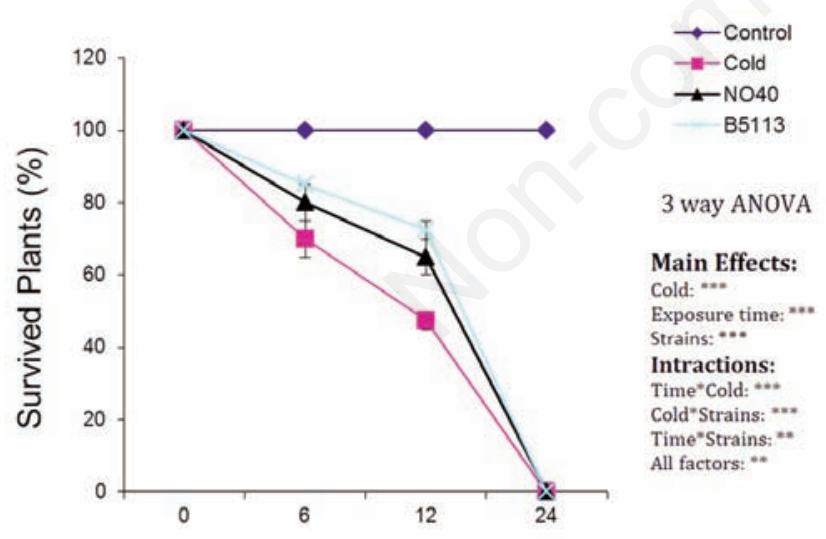

Exposure time (h)
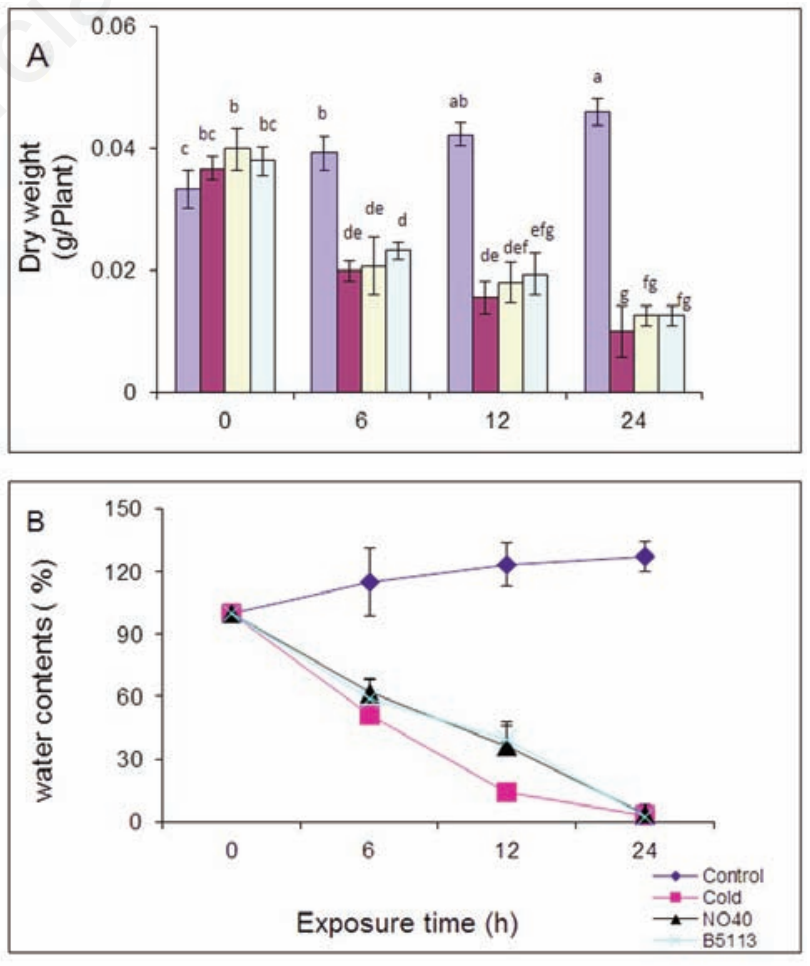

Figure 2. Effect of bacterial priming on some growth parameters of chilling stressed wheat Bacterial priming with $B$. amyloliquefaciens 5113 or $A$. brasilense NO40 were tested for effects on growth parameters of wheat seedlings (cv. Sids 1) subjected to $-5^{\circ} \mathrm{C}$ chilling stress for $0,6,12$ and $24 \mathrm{~h}$. Bars indicate standard errors between six replicates. Treatments labelled with identical letters are not significant at $P \leq 0.01$. A) Shoot dry weight (g/plant); B) shoot water content (\%). 
resulted in a massive decrease in the survival rate where $40 \%$ survival rate was recorded after $12 \mathrm{~h}$ of exposure to $-5^{\circ} \mathrm{C}$, when bacterial treatment significantly improved the survival rate and growth of stressed wheat (Figure 1). The effect of both PGPB strains tested on the survival rate under freezing conditions was in the range between $60 \%$ to $80 \%$ for seedlings exposed to $-5^{\circ} \mathrm{C}$ for $12 \mathrm{~h}$. Increasing the exposure time to $24 \mathrm{~h}$ caused irreversible damage with no survivors in any of the test groups.

Under cold stress conditions, wheat dry weight declined dramatically (Figure 2A). Dry weight was significantly decreased by exposing wheat to $-5^{\circ} \mathrm{C}$ stress but increasing the exposure time up to $24 \mathrm{~h}$ did not significantly affect the decline in dry weight. In most cases, both bacterial strains used for priming showed a slight increase in the accumulation of dry matter in the cold stressed wheat seedlings compared with their unprimed counterparts.

Exposing wheat to $-5^{\circ} \mathrm{C}$ resulted in a significant decrease in water content which correlated with the exposure time to freezing. After 24 $\mathrm{h}$ of cold stress severe losses in water content were recorded. Bacterial priming greatly counteracted the decrease in water content.
Priming with B. amyloliquefaciens 5113 improved the water content of the seedlings exposed for $12 \mathrm{~h}$ to cold stress more than twofold from 15 to $39 \%$ (Figure 2B).

\section{Enzymes of the ascorbate-glu- tathione redox cycle}

The APX activity increased significantly in the leaves of all cold stressed seedlings whatever primed or not and this was in parallel with the increase of exposure time. $B$. amyloliquefaciens 5113 primed seedlings showed lower APX activity in the leaves compared with the un-primed stressed seedlings (Figure 3A). Exposing wheat seedlings to $-5^{\circ} \mathrm{C}$ caused a marked increase in the activity of DHAR in the leaves at all time points (Figure 3B). It was also noticed that the effect of bacterial priming appeared as decreased activity of this enzyme in wheat leaves. Cold stress resulted in increasing MDHAR activity in the leaves of all stressed wheat seedlings (Figure 3C). Bacterial priming resulted in a slight increase in the MDHAR activity in leaf tissue compared with their un-primed stressed counterparts. Exposing wheat seedlings to freezing led to a significant increase in the activity of GR in the leaves (Figure 3D). The highest GR activity was observed after $6 \mathrm{~h}$ of cold stress. GR activity was significantly decreased in the leaves of B. amyloliquefaciens primed seedlings compared with un-primed cold stressed seedlings.

\section{Molecular stress markers}

Transcript levels of the stress marker genes APX1, SAMS1 and HSP17.8 were measured in leaves using RT-PCR. Results indicated that exposing wheat seedlings to cold stress for $6 \mathrm{~h}$ led to a significant up-regulation of the APX1 gene for all stress treatments which reached maximal levels after $12 \mathrm{~h}$. The effect of bacterial treatment on APX1 expression in stressed wheat leaves varied among the strains tested for priming. B. amyloliquefaciens 5113 treatment significantly decreased $A P X 1$ levels in all stressed seedlings while for $A$. brasilense N040 treated seedlings, APX1 expression was not different compared with un-primed stressed plants (Figure 4A).

Exposing wheat to $-5^{\circ} \mathrm{C}$ significantly increased the expression of SAMS1 in the leaves in all treatments. It was also observed

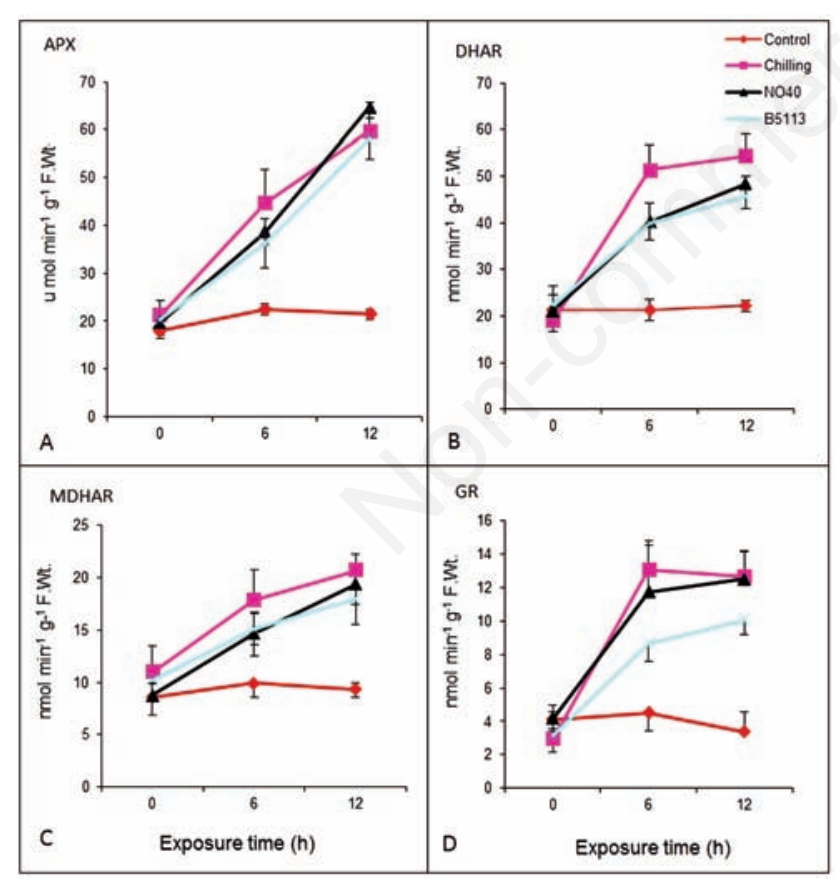

Figure 3. Effect of bacterial priming on the activity of redox enzymes in the leaves of cold stressed wheat Effects of priming with $B$. amyloliquefaciens 5113 or A. brasilense NO40 on the activity of enzymes of the ascorbate-glutathione redox cycle were tested in the leaves of wheat seedlings (cv. Sids1) exposed to $-5^{\circ} \mathrm{C}$ for 0, 6 and 12 h. A) Ascorbate Peroxidase (APX) (umol min-1 $\mathrm{g}^{-1}$ fresh weight); B) dehydroascorbate reductase (DHAR); C) mono-dehydroascorbate reductase (MDHAR); and D) glutathione reductase (GR) (nmol min-1 $\mathrm{g}^{-1}$ fresh weight). Bars indicate standard errors between 3 replicates.

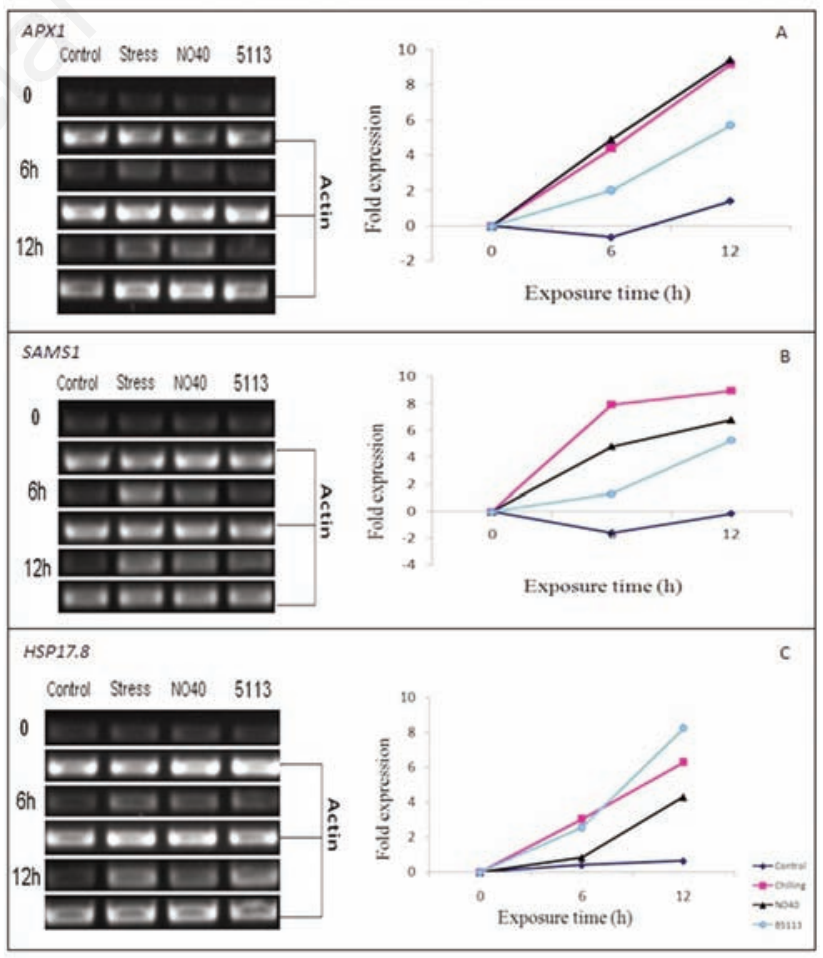

Figure 4. RT-PCR analysis of some stress marker genes in cold stressed wheat leaves. Wheat plants (cv. Sids1) pretreated with $B$. amyloliquefaciens $5113(\bullet)$ or A. brasilense (A) NO40 were exposed to $-5^{\circ} \mathrm{C}$ for 0,6 and $12 \mathrm{~h}$. Semi-quantitative RT-PCR analysis was used to study steady state levels of $A P X 1$ (A), SAMS1(B) and HSP17.8 (C) expression. The cytoskeleton gene ACTIN was used to normalize expression levels. The expression is shown as the relative fold expression to the control $(\diamond)$ at zero time. Cold treated plants without priming served as stress positive control ( $\square)$. 
that the SAMS1 gene was responding immediately to low temperature and the expression level was always elevated with increasing stress exposure time. Generally, bacterial primed seedlings showed lower SAMS1 levels in the leaves compared with the unprimed stressed seedlings. However, B. amyloliquefaciens 5113 primed seedlings showed much lower SAMS1 levels compared to A. brasilense NO40 primed seedlings (Figure 4B).

Low temperature significantly induced the transcript levels of HSP17.8 in wheat leaves. There was no difference in HSP17.8 levels in wheat leaves when cold stressed seedlings (6 h) was compared with $B$. amyloliquefaciens 5113 primed seedlings under the same stress conditions. On the other hand, A. brasilense N040 primed seedlings showed lower HSP17.8 expression under cold stress conditions compared with its un-primed stressed seedlings (Figure 4C).

\section{Discussion}

We chose to test low temperature tolerance without acclimation since diurnal temperature variation may vary strongly in Egypt for spring cultivars. In the present study strong stress symptoms were displayed already after $6 \mathrm{~h}$ at $-5^{\circ} \mathrm{C}$ with hanging leaves and later discolouring as well as a decline in plant growth and survival that was more pronounced after prolonged cold stress. After three days of recovery the surviving plants looked healthier and with somewhat better phenotype for the primed plants. Plant growth reduction caused by low temperature is usually a result of damage due to acute dehydration associated with freezing. ${ }^{4}$ Such dehydration effects were evident from our results where dramatic losses in leaf water content were observed after exposure to freezing temperatures. On the other hand, in accordance with our hypothesis, we could show that bacterial priming significantly counteracted the deleterious effects of low temperature on plant survival and growth after 6 and $12 \mathrm{~h}$ of cold treatment. Although it is a well-known fact that certain bacteria promote stress tolerance of plants the mechanisms often remain unknown. ${ }^{5,13}$ However, a recent study, ${ }^{14}$ demonstrating priming of cold tolerance in wheat by Pseudomonads, attributed the effect to improved photosynthetic capacity and enhanced root growth due to bacterial IAA production. It is known that IAA can be produced by $A$. brasilense and $B$. amyloliquefaciens. ${ }^{15,16}$ We observed a somewhat greater root system on the bacteria treated plants suggesting that the tested strains indeed could be working according to a similar mechanism.

Counteracting oxidative stress is critical in order to avoid cell damage. In the present study we observed a significant increase in the activities of four antioxidant enzymes in wheat leaves experiencing freezing. In general higher antioxidant capacities correlate with elevated ROS generation. We showed that bacterial primed and stressed plants had considerably lower antioxidant enzyme activity in the leaves compared with their unprimed stressed counterparts, which suggests that priming decrease ROS generation upon stress challenge. It may be that photosynthesis, respiration and photorespiration are under better control at stress as a result of priming. Lowering of ROS levels is also important to prevent signalling for cell death. ${ }^{17}$ To overcome cold stress, modifications in plant metabolism are required, e.g. synthesis of cryoprotectants. ${ }^{3}$ We detected a significant up-regulation of SAMS1 transcript levels in wheat leaves after low temperature treatment. Similar results were reported by recording elevated transcription for all $\mathrm{C} 1$ biosynthetic genes in the leaves of cold stressed wheat. ${ }^{18}$ In the present study, it was noticed that bacterial treated and stressed seedlings had lower SAMS1 transcript levels compared with their unprimed counterparts suggesting lower supply of methyl units and associated metabolite tuning. This could imply that the plant becomes more specific in production of protective molecules to prevent cold induced damage or those other factors are more important in primed cold tolerance. Metabolomic analysis of cold responses in plants, mostly Arabidopsis, generally showed reprogramming but for many changes the functional role remains unclear. ${ }^{19}$ Many metabolites associated with cold stress are of unknown structure pointing to the role of yet unknown pathways for abiotic stress tolerance. ${ }^{19}$ Most probably a combination of protective metabolites in consort with proteins are needed for appropriate temperature stress control and stress tolerant cultivars often contain higher levels of dehydrins or other stress related proteins. ${ }^{20}$

Protein folding is usually compromised by low temperatures limiting the functionality of cells. ${ }^{21}$ In the present study, HSP17.8 transcript levels were highly up-regulated in wheat leaves exposed to cold stress showing a greater need to support protein folding. However, Azospirillum primed and stressed seedlings showed lower levels of HSP17.8 suggesting that a more favourable environment for protein folding and stability exists in the primed plants.

Obviously regulation of gene expression is a key issue for plants to develop stress tolerance. Various forms of abiotic stress responses share some common regulatory features in addition to unique responses. ${ }^{22}$ However, changes in temperature often occur more rapidly than other abiotic stresses like drought and salinity requiring more rapid compensatory systems in the plant. Analysis of transcript responses show that distinct sets of genes are modulated by different cold treatments but the present limitation of genome information for non-model organisms restrict in depth analysis. ${ }^{19}$ However, a role for WRKY and NAC transcription factors for cold stress tolerance in wheat has been shown. ${ }^{23,24}$ In Arabidopsis the NAC NTL4 gene controls ROS generation in drought so down regulation of wheat ortholog could help to explain the primed cold stress effects on ROS. ${ }^{25}$ Exposure to a low temperature for a shorter duration generally improves cold tolerance of plants (acclimation) while a longer time period of cold (vernalization) is needed for many plants to initiate reproductive growth. While adjustments to low temperatures would be expected to involve similar mechanisms, a recent investigation showed that cold acclimation and vernalization responses differ. ${ }^{26}$ Another study in Arabidopsis showed that changes in transcriptome but not metabolome correlated with ability to cold acclimate while for freezing tolerance both metabolite and transcript changes was correlated illustrating the complexity of plant responses to different low temperature regimes. ${ }^{27}$

\section{Conclusions}

In conclusion, we have demonstrated the potential of using two bacterial strains to prime abiotic stress tolerance and enhance growth of wheat experiencing low temperature, which supported our hypothesis that bacteria which counteract one type of water stress (drought and heat) also can work on other types of water related stress (cold). The data showed varying impact on the ascorbate-glutathione redox cycle, $\mathrm{Cl}$ generation and the expression of small HSPs indicating that priming support stress tolerance by several changes at metabolite and protein level when plants become challenged. Future analysis need to identify factors that are needed for priming of stress tolerance to optimize this biotechnology.

\section{References}

1. Gill SS, Tuteja N. Reactive oxygen species and antioxidant machinery in abiotic stress tolerance in crop plants. Plant Physiol Biochem 2010; 48:909-30.

2. Hanson $\mathrm{AD}$, Roje S. One carbon metabolism in higher plants. Annu Rev Plant Physiol Plant Mol Biol 2001; 52:119-37.

3. Janská A, Maršik P, Zelenková S, Ovensá J. Cold stress and acclimation- what is important for metabolic adjustment? Plant Biol 2010;12:395-405. 
4. Mahajan S, Tuteja N. Cold, salinity and drought stresses: an overview. Arch Biochem Biophys 2005;444:139-58.

5. Dimkpa C, Weinand T, Asch F. PlantRhizobacteria interactions alleviate abiotic stress conditions. Plant Cell Environ 2009;32:1682-94.

6. Kasim WA, Osman ME, Omar MN, et al. Control of drought stress in wheat using plant-growth-promoting bacteria. J Plant Growth Regul 2013;32:122-30.

7. Abou-Deif MH, Mohamed FI. Effect of heat stress on chromosomes and protein patterns in six hexaploid wheat varieties. Res J Cell Mol Biol 2007;1:42-9.

8. Miche L, Balandreau J, Effects of rice seed surface sterilization with hypochlorite on inoculated Burkholderia vietnamiensis. Appl Environ Microb 2001;67:3046-52.

9. Omar MNA, Osman MEH, Kasim WA, Abd El-Daim IA. Improvement of salt tolerance mechanisms of barley cultivated under salt stress using Azospirillum brasilense. In: Ashraf M, Ozturk M, Athar HR, eds. Salinity and water stress improving crop efficiency. Dordrecht: Springer Verlag; 2009. pp. 133-147

10. Danielsson J, Reva 0, Meijer J. Protection of oilseed rape (Brassica napus) toward fungal pathogens by strains of plant-associated Bacillus amyloliquefaciens. Microb Ecol 2009;54:134-40.

11. Murshed R, Lopez-Lauri F, Sallanon H. Microplate quantification of enzymes of the plant ascorbate-glutathione cycle. Anal Biochem 2008;383:320-2.

12. Rozen S, Skaletsky H. Primer3 on the WWW for general users and for biologist programmers. Meth Mol Biol 2000;132:
365-86.

13. Yang J, Kloepper JW, Ryu C. Rhizosphere bacteria help plants tolerate abiotic stress. Trends Plant Sci 2009;14:1-4.

14. Mishra PK, Bisht SC, Ruwari P, et al. Allevation of cold stress in inoculated wheat (Triticum aestivum L.) seedlings with psychrotolerant Pseudomonads from NW Himalayas. Arch Microb 2011;193:497513.

15. Tien TM, Gaskins MH, Hubbell DH. Plant growth substances produced by Azospirillum brasilense and their effect on the growth of pearl millet (Pennisetum americanum L.). Appl Environ Microb 1979; 37:1016-24.

16. Idris EE, Iglesias DJ, Talon M, Borriss R. Tryptophan-dependent production of indole-3-acetic acid (IAA) affects level of plant growth promotion by Bacillus amyloliquefaciens FZB42. Mol Plant Microbe Interact 2007;20:619-26.

17. Jaspers P, Kangasjärvi J. Reactive oxygen species in abiotic stress signaling. Physiol Plant 2010;138:405-13.

18. Bhuiyan NH, Liu W, Liu G, et al. Transcriptional regulation of genes involved in the pathways of biosynthesis and supply of methyl units in response to powdery mildew attack and abiotic stresses in wheat. Plant Mol Biol 2007;64:305-18.

19. Hincha DK, Espinoza C, Zuther E. Transcriptomic and metabolomic approaches to the analysis of plant freezing tolerance and cold acclimation in improving crop resistance to abiotic stress. In: Tuteja N, Gill SS, Tiburcio AF, Tuteja R, eds. Improving crop resistance to abiotic stress. Weinheim: Wiley-VCH
Verlag $\mathrm{GmbH} \& \mathrm{Co} ; 2012$.

20. Hanin M, Brini F, Ebel C, et al. Plant dehydrins and stress tolerance: versatile proteins for complex mechanisms. Plant Signal Behav 2011;6:1503-09.

21. Timperio AM, Egidi MG, Zolla L. Proteomics applied on plant abiotic stresses: Role of heat shock proteins (HSP). J Proteom 2008;71:391-11.

22. Qin F, Shinozaki K, Yamaguchi-Shinozaki $\mathrm{K}$. Achievements and challenges in understanding plant abiotic stress responses and tolerance. Plant Cell Physiol 2011;52: 1569-82.

23. Niu CF, Wei W, Zhou QY, et al. Wheat WRKY genes TaWRKY2 and TaWRKY19 regulate abiotic stress tolerance in transgenic Arabidopsis plants. Plant Cell Environ 2012;35:1156-70.

24. Mao X, Zhang H, Qian X, et al. TaNAC2, a NAC-type wheat transcription factor conferring enhanced multiple abiotic stress tolerances in Arabidopsis. J Exp Bot 2012;63:2933-46.

25. Lee S, Seo PJ, Lee HJ, Park CM. A NAC transcription factor NTL4 promotes reactive oxygen species production during drought-induced leaf senescence in Arabidopsis. Plant J 2012;70:831-44.

26. Bond DM, Dennis ES, Fonnegan EJ. The low temperature response pathways for cold acclimation and vernalization are independent. Plant Cell Environ 2011;34: 1737-48.

27. Hannah MA, Wiese D, Freund S, et al. Natural genetic variation of freezing tolerance in Arabidopsis. Plant Physiol 2006; 142:98-111. 